Research article

Open Access

\title{
TP53-binding protein variants and breast cancer risk: a case-control study
}

\author{
Bernd Frank ${ }^{1}$, Kari Hemminki ${ }^{1,2}$, Justo Lorenzo Bermejo ${ }^{1}$, Rüdiger Klaes ${ }^{3}$, Peter Bugert ${ }^{4}$, \\ Barbara Wappenschmidt ${ }^{5}$, Rita K Schmutzler ${ }^{5}$ and Barbara Burwinkel ${ }^{1}$
}

\author{
1'Division of Molecular Genetic Epidemiology, German Cancer Research Center (DKFZ), Heidelberg, Germany \\ 2Department of Biosciences at Novum, Karolinska Institute, Huddinge, Sweden \\ IInstitute of Human Genetics, University of Heidelberg, Heidelberg, Germany \\ 4 Institute of Transfusion Medicine and Immunology, Red Cross Blood Service of Baden-Württemberg-Hessia, University of Heidelberg, Faculty of \\ Clinical Medicine, Mannheim, Germany \\ ${ }^{5}$ Division of Molecular Gynaeco-Oncology, Department of Gynaecology and Obstetrics, Clinical Center University of Cologne, Germany
}

Corresponding author: Bernd Frank, b.frank@dkfz.de

Received: 25 Feb 2005 Revisions requested: 17 Mar 2005 Revisions received: 23 Mar 2005 Accepted: 12 Apr 2005 Published: 6 May 2005

Breast Cancer Research 2005, 7:R502-R505 (DOI 10.1186/bcr1038)

This article is online at: http://breast-cancer-research.com/content/7/4/R502

(C) 2005 Frank et al.; licensee BioMed Central Ltd.

This is an Open Access article distributed under the terms of the Creative Commons Attribution License (http://creativecommons.org/licenses/by/ 2.0), which permits unrestricted use, distribution, and reproduction in any medium, provided the original work is properly cited.

\begin{abstract}
Introduction The TP53-binding protein (53BP1) has been shown to influence TP53-mediated transcriptional activation, thus playing a pivotal role in DNA damage signalling. Genetic aberrations in TP53 and in ATM and CHEK2 predispose to cancer. We have therefore examined the effects of 53BP1 single nucleotide polymorphisms (D353E, G412S, and $\mathrm{K} 1136 \mathrm{Q})$ and the novel 53BP1 6bp deletion (1347_1352delTATCCC) on breast cancer risk.

Methods Allelic discrimination was performed to investigate the frequencies of 53BP1 D353E, G412S, and K1136Q and of 1347_1352delTATCCC in 353 patients with breast cancer and 960 control individuals.

Results No significant association of 53BP1 D353E, G412S, or $\mathrm{K} 1136 \mathrm{Q}$ with breast cancer risk was detected. 53BP1 1347_1352delTATCCC, leading to the loss of an isoleucine and a proline residue, showed a nonsignificant inverse association with breast cancer risk (odds ratio $=0.61,95 \%$ confidence interval $=0.22$ to $1.68, P=0.34$ ).

Conclusion The lack of association casts doubt on the putative effects of D353E, G412S, and K1136Q on breast cancer risk. Investigating a larger study cohort might elucidate the influence of the $6 \mathrm{bp}$ deletion 1347_1352delTATCCC. Studying the functional effect and the impact of this variant on the risk of other cancers may be revealing.
\end{abstract}

\section{Introduction}

The TP53-binding protein (53BP1), a conserved nuclear protein, was initially identified to interact with the DNA-binding domain of TP53, thus enhancing TP53-mediated transcriptional activation $[1,2]$. In response to exogenous exposure to ionising radiation, 53BP1 becomes hyperphosphorylated and rapidly localises to sites of DNA double-strand breaks, demonstrating its determining role in DNA damage signalling [3,4]. 53BP1-deficient mice exhibit growth retardation, high radiation sensitivity, and tumour development - features that are indicative of a defective DNA damage response [5]. 53BP1 is involved in the phosphorylation of various ataxia telangiectasia mutated protein (ATM) substrates such as cell cycle check- point kinase 2 (CHEK2) [3,6]. Mutations in ATM, CKEK2, and its substrate, TP53, have been shown to predispose to cancer [6-9]. Therefore, we selected $53 B P 1$ as an attractive candidate gene for breast cancer susceptibility.

This is the first study to investigate the effects of the 53BP1 single nucleotide polymorphisms (SNPs) D353E (1059C>G), G412S (1234G>A), and K1136Q (3406A>C) on breast cancer risk, analysing 353 German patients with breast cancer and 960 controls. 53BP1 D353E, G412S, and K1136Q showed no association with breast cancer risk. In addition, we detected a novel, very rare 53BP1 $6 \mathrm{bp}$ deletion (1347_1352delTATCCC) showing an inverse association 
with breast cancer risk (age-adjusted odds ratio $(\mathrm{OR})=0.61$, $95 \%$ confidence interval $(\mathrm{Cl})=0.22$ to 1.68$)$, lacking significance $(P=0.34)$.

\section{Materials and methods SNP verification}

A randomly chosen set of 23 German patients with familial breast cancer was initially screened for annotated 53BP1 SNPs (dbSNP database; NCBI (National Center for Biotechnology Information)) by DNA sequencing. Sequencing primers are available upon request. The initial analysis included 53BP1 exons 9,11 , and 17 , harbouring three reported nonsynonymous polymorphisms (D353E: rs560191; G412S: rs689647; and K1136Q: rs2602141). When sequencing exon 11, we additionally detected the 6bp deletion 1347_1352deITATCCC. All validated variants were chosen for further analyses using a large cohort of breast cancer patients.

\section{Subjects}

The breast cancer patients were 353 unrelated German women (mean age 44.8 years, range 21 to 80 years) who were negative for $B R C A 1$ and $B R C A 2$ mutations. In accordance with the German Consortium for Hereditary Breast and Ovarian Cancer, they were classified into six categories based on family history: (A1) families with two or more breast cancer cases including two cases with onset below the age of 50 (39.3\% of analysed cases); (A2) families with at least one male breast cancer case $(0.9 \%)$; (B) families with at least one breast cancer and one ovarian cancer case (16.2\%); (C) families with at least two breast cancer cases including one case diagnosed before the age of 50 (33.5\%); (D) families with at least two breast cancer cases comprising two cases diagnosed after the age of $50(5.5 \%)$; (E) single cases of breast cancer diagnosed before the age of $35(4.6 \%)$ [10]. They were collected during the years 1997 to 2004 through the Institute of Human Genetics (Heidelberg, Germany) and the Department of Gynaecology and Obstetrics (Cologne, Germany). The control series included 960 blood donors (mean age 30.5 years, range 18 to 67 years) collected by the Institute of Transfusion Medicine and Immunology (Mannheim, Germany) having the same ethnic background as the breast cancer patients. Both study populations have been described earlier [11]. The study was approved by the Ethics Committee of the University of Heidelberg (Heidelberg, Germany).

PCR amplification and sequencing were performed as previously described [11]. Conditions are available on request.

\section{Genotyping}

53BP1 polymorphisms D353E, G412S, and K1136Q were analysed using TaqMan allelic discrimination. TaqMan assays were performed in a reaction volume of $10 \mu \mathrm{l}$ comprising $5 \mathrm{ng}$ of genomic DNA, each probe at $50 \mathrm{nM}$, each primer at 225 $\mathrm{nM}$, and $1 \times$ Universal Master Mix with the following amplifica- tion conditions: $2 \mathrm{~min}$ at $50^{\circ} \mathrm{C}, 10 \mathrm{~min}$ at $95^{\circ} \mathrm{C}$ and 35 to 45 cycles at $92^{\circ} \mathrm{C}$ for $15 \mathrm{~s}$ and $60^{\circ} \mathrm{C}$ for $1 \mathrm{~min}$. Amplification products were measured and analysed with the ABI Prism 7900 $\mathrm{HT}$ sequence detection system and the SDS software (version 1.2; Applied Biosystems, Foster City, CA, USA). TaqMan probes and primers were provided by the assay-on-demand and assay-by-design services, respectively (Applied Biosystems). 53BP1 1347_1352delTATCCC was analysed using the MGB Eclipse ${ }^{\mathrm{TM}}$ Probe System by Epoch Biosciences (Bothell, WA, USA). Allelic discrimination was carried out as recommended by the manufacturers using the following probes: D353E: assay-on-demand C_2944794_10; G412S: VIC-ACTTCAAAGTGGTGAACC, FAM-AACTTCAAAGTAGTGAACC; K1136Q: VIC-GGAGTACTAATAAGGAAA, FAM-CGGAGTACTAATCAGGAAA; 1347_1352delTATCCC: FAM-CACTTCATCCCAT; TETCACTTCCTATCCCATC. Primers and probes were designed based on GenBank NM_005657 (NCBI) and are available on request. More than $5 \%$ of the genotyping results were confirmed by sequencing, and genotype distributions were consistent with Hardy-Weinberg equilibrium.

\section{Statistical methods}

Calculations of Hardy-Weinberg equilibrium, genotype-specific OR, and $95 \% \mathrm{Cl}$ were carried out using a tool offered by the Institute of Human Genetics, Technical University Munich, Munich, Germany [12]. Age-adjusted ORs and corresponding 95\% Cls were computed by means of unconditional logistic regression using SAS (Version 8.2; SAS Institute Inc, Cary, NC, USA). Haplotypes were assigned to subjects using the SNPHAP software (see [13]), which also reports the posterior probability of the most likely assignment $[14,15]$.

\section{Results and discussion}

Inactivation of ATM and ATM substrates such as CHEK2 have been shown to predispose to cancer in humans [7]. Along with ATM and CHEK2, 53BP1 is involved in DNA damage response and tumour suppression. Recent studies have shown that 53BP1 and ATM interact in irradiated cells, suggesting that ATM activation is the consequence of the recruitment of ATM to sites of DNA double-strand breaks by 53BP1 $[7,9]$. Thus, polymorphic variants in 53BP1 are excellent candidates for cancer susceptibility. We investigated the impact of three nonsynonymous amino acid exchanges in 53BP1 on breast cancer risk. 53BP1 G413S and K1136Q represented promising candidate SNPs, resulting in the replacement of a nonpolar by a polar amino acid. Genotype frequencies of the three 53BP1 polymorphisms between breast cancer cases and control samples were similar, showing no significant association with breast cancer risk (D353E: age-adusted OR = $1.07,95 \% \mathrm{Cl}=0.81$ to $1.43, P=0.62 ; \mathrm{G} 412 \mathrm{~S}$ : age-adjusted $\mathrm{OR}=1.22,95 \% \mathrm{Cl}=0.86$ to $1.74, P=0.26 ; \mathrm{K} 1136 \mathrm{Q}$ : ageadjusted $\mathrm{OR}=1.10,95 \% \mathrm{Cl}=0.82$ to $1.47, P=0.53$; Table 1). Aditionally, we detected a novel 53BP1 6 bp deletion, 1347_1352delTATCCC, leading to the loss of an isoleucine 
Table 1

\begin{tabular}{|c|c|c|c|c|}
\hline Polymorphism & No. (\%) of cases & No. (\%) of controls & AOR $(95 \% \mathrm{Cl})$ & $P$ \\
\hline \multicolumn{5}{|l|}{ D353E (1059C>G) } \\
\hline $\mathrm{CC}$ & $165(48.1)$ & $453(47.6)$ & & \\
\hline GC & $148(43.1)$ & $405(42.5)$ & & \\
\hline GG & $30(8.7)$ & $94(9.9)$ & & \\
\hline$\Sigma$ & 343 & 952 & & \\
\hline $\mathrm{CC}$ vs $\mathrm{GC}+\mathrm{GG}$ & & & $1.07(0.81-1.43)$ & 0.62 \\
\hline \multicolumn{5}{|l|}{$\mathrm{G} 412 \mathrm{~S}(1234 \mathrm{G}>\mathrm{A})$} \\
\hline GG & $269(78.7)$ & $760(80.1)$ & & \\
\hline AG & $67(19.6)$ & $174(18.3)$ & & \\
\hline$A A$ & $6(1.8)$ & $15(1.6)$ & & \\
\hline$\Sigma$ & 342 & 949 & & \\
\hline$A A+A G$ vs $G G$ & & & $1.22(0.86-1.74)$ & 0.26 \\
\hline \multicolumn{5}{|l|}{ 1347_1352delTATCCC } \\
\hline wt/wt & $334(98.2)$ & $931(97.4)$ & & \\
\hline delTATCCC/wt & $6(1.8)$ & $25(2.6)$ & & \\
\hline delTATCCC/delTATCCC & $0(0.0)$ & $0(0.0)$ & & \\
\hline$\Sigma$ & 340 & 956 & & \\
\hline delTATCCC/wt vs wt/wt & & & $0.61(0.22-1.68)$ & 0.34 \\
\hline \multicolumn{5}{|l|}{ K1136Q $(3406 \mathrm{~A}>\mathrm{C})$} \\
\hline$A A$ & $158(47.4)$ & $448(47.8)$ & & \\
\hline $\mathrm{CA}$ & $144(43.2)$ & $396(42.2)$ & & \\
\hline $\mathrm{CC}$ & $31(9.3)$ & $94(10.0)$ & & \\
\hline$\Sigma$ & 333 & 938 & & \\
\hline $\mathrm{CC}+\mathrm{CA}$ vs $\mathrm{AA}$ & & & $1.10(0.82-1.47)$ & 0.53 \\
\hline
\end{tabular}

$\mathrm{AOR}$, age-adjusted odds ratio; $\mathrm{Cl}$, confidence interval; wt, wild type.

Table 2

Haplotype distribution of 53BP1 polymorphismsa in breast cancer patients and control individuals

\begin{tabular}{|c|c|c|c|c|c|c|c|}
\hline \multirow[b]{2}{*}{$\begin{array}{l}\text { Haplotype } \\
\text { 1059C>G-1234G } \\
>\text { A-1347_1352//+-3406A>C }\end{array}$} & \multicolumn{2}{|c|}{ Cases } & \multicolumn{2}{|c|}{ Controls } & \multirow[t]{2}{*}{$\mathrm{OR}^{\mathrm{b}}$} & \multirow[t]{2}{*}{$95 \% \mathrm{Cl}$} & \multirow[t]{2}{*}{$P$} \\
\hline & No. (\%) & $\begin{array}{l}\text { Mean posterior } \\
\text { probability }\end{array}$ & No. (\%) & $\begin{array}{l}\text { Mean posterior } \\
\text { probability }\end{array}$ & & & \\
\hline $\mathrm{CG}+\mathrm{A}$ & $444(68.1)$ & 1 & $1242(67.5)$ & 1 & 1 & - & - \\
\hline $\mathrm{CG}+\mathrm{C}$ & $2(0.3)$ & 1 & $1(0.1)$ & 1 & n.a. & n.a. & n.a. \\
\hline CG-A & $6(0.9)$ & 0.90 & $25(1.4)$ & 0.99 & 0.63 & $0.23-1.75$ & 0.38 \\
\hline $\mathrm{GG}+\mathrm{A}$ & $1(0.2)$ & 1 & $1(0.1)$ & 1 & n.a. & n.a. & n.a. \\
\hline$G G+C$ & $125(19.2)$ & 1 & $376(20.4)$ & 1 & 1.02 & $0.79-1.33$ & 0.86 \\
\hline $\mathrm{GA}+\mathrm{C}$ & $74(11.3)$ & 1 & $195(10.6)$ & 1 & 1.15 & $0.83-1.61$ & 0.41 \\
\hline
\end{tabular}


and a proline residue at positions 450 and 451 , which has not been described previously. Comparing the occurrence of this rare, 6 bp deletion between cases and controls revealed an inverse association with breast cancer risk (OR $=0.61,95 \%$ $\mathrm{Cl}=0.22$ to $1.68, P=0.34$; Table 1 ), but lacking statistical significance.

The haplotype distribution and corresponding posterior probabilities are shown in Table 2. Since every mean posterior probability was higher than 0.9 , only the most likely haplotypes were used to evaluate the association with breast cancer risk. Haplotype analysis showed a nonsignificant inverse association of the haplotype 1059C-1234G-1347_1352-3406A with breast cancer risk (age-adjusted $\mathrm{OR}=0.63,95 \% \mathrm{Cl}=$ 0.23 to $1.75, P=0.38$; Table 2). The distribution of the remaining haplotypes between breast cancer patients and controls was similar, indicating no significant effect with regard to breast cancer risk. Given our sample size, we had a $90 \%$ power to detect an odds ratio of 1.65 (D353E), 1.76 (G412S), and 1.66 (K1136Q), respectively [16]. Contrary to standard case-control association studies, this study comprised predominantly cases selected for family history of breast cancer. The use of unselected cases would have required at least twice the sample size to achieve the same power as in the present study $[17,18]$. The numbers of cases within the risk groups $A 1$ to $E$ were too low to be studied separately, as the power in these subgroups would have been limited. In addition to the results of this study, one cannot exclude the possibility that common 53BP1 SNPs may affect breast cancer risk. Regulatory polymorphisms, for example polymorphisms that reside in promotor or noncoding regions, have been shown to modify gene transcription, mRNA stability, and processing efficiency, as well as DNA methylation $[19,20]$.

\section{Conclusion}

The three known 53BP1 SNPs - D353E, G412S, and $\mathrm{K} 1136 \mathrm{Q}$ - lacked association with breast cancer risk. However, we detected a novel, very rare $6 \mathrm{bp}$ deletion, 1347_1352deITATCCC, that showed a statistically nonsignificant inverse association with breast cancer risk. Concerning the latter, a much larger study cohort is required to verify any putative significant effect. Additionally, it would be valuable to investigate a possible functional effect of this $53 B P 1$ deletion and its impact on other cancers.

\section{Competing interests}

The author(s) declare that they have no competing interests.

\section{Authors' contributions}

All authors listed contributed to the production of this manuscript: RK, PB, BW, and RKS provided genomic DNAs of cases studied and helped to draft the manuscript. BB and $\mathrm{KH}$ participated in the design and coordination of the study and critically revised the manuscript. BF and JLB performed statis- tical analyses. BF carried out the SNP genotyping and wrote the manuscript. All authors read and approved the final manuscript.

\section{Acknowledgements}

The authors wish to thank Kerstin Wagner for critical comments on the manuscript and are grateful to Prof CR Bartram (Heidelberg) and Prof RK Schmutzler (Cologne) for providing the German breast cancer samples, which were collected within a project funded by the Deutsche Krebshilfe.

\section{References}

1. Iwabuchi K, Bartel PL, Li B, Marraccino R, Fields S: Two cellular proteins that bind to wild-type but not mutant p53. Proc Natl Acad Sci USA 1994, 91:6098-6102.

2. Iwabuchi K, Li B, Massa HF, Trask BJ, Date T, Fields S: Stimulation of p53-mediated transcriptional activation by the p53binding proteins, 53BP1 and 53BP2. J Biol Chem 1998, 273:26061-26068.

3. Rappold I, Iwabuchi K, Date T, Chen J: Tumor suppressor p53 binding protein 1 (53BP1) is involved in DNA damage-signaling pathways. J Cell Biol 2001, 153:613-620.

4. Wang B, Matsuoka S, Carpenter PB, Elledge SJ: 53BP1, a mediator of the DNA damage checkpoint. Science 2002, 298:1435-1438.

5. Ward IM, Minn K, van Deursen J, Chen J: p53 Binding protein 53BP1 is required for DNA damage responses and tumor suppression in mice. Mol Cell Biol 2003, 23:2556-2563.

6. CHEK2-Breast Cancer Consortium: Low-penetrance susceptibility to breast cancer due to CHEK2 $\left(^{*}\right) 1100 \mathrm{deIC}$ in noncarriers of BRCA1 or BRCA2 mutations. Nat Genet 2002, 31:55-59.

7. DiTullio RA Jr, Mochan TA, Venere M, Bartkova J, Sehested M, Bartek J, Halazonetis TD: 53BP1 functions in an ATM-dependent checkpoint pathway that is constitutively activated in human cancer. Nat Cell Biol 2002, 4:998-1002.

8. Vorechovsky I, Luo L, Lindblom A, Negrini M, Webster AD, Croce $\mathrm{CM}$, Hammarstrom L: ATM mutations in cancer families. Cancer Res 1996, 56:4130-4133.

9. Mochan TA, Venere M, DiTullio RA Jr, Halazonetis TD: 53BP1, an activator of ATM in response to DNA damage. DNA Repair 2004, 3:945-952

10. Meindl A, and German Consortium for Hereditary Breast and Ovarian Cancer: Comprehensive analysis of 989 patients with breast or ovarian cancer provides BRCA1 and BRCA2 mutation profiles and frequencies for the German population. Int $J$ Cancer 2002, 97:472-480.

11. Frank $B$, Hemminki $K$, Wirtenberger $M$, Bermejo JL, Bugert $P$, Klaes R, Schmutzler RK, Wappenschmidt B, Bartram CR, Burwinkel B: The rare ERBB2 variant Ile654Val is associated with an increased familial breast cancer risk. Carcinogenesis 2005, 26:643-647.

12. Hardy-Weinberg equilibrium [http://ihg.gsf.de/cgi-bin/hw/ hwa1.pl]

13. Software and course materials [http://wwwgene.cimr.cam.ac.uk/clayton/software/]

14. Schaid DJ: Evaluating associations of haplotypes with traits Genet Epidemio/ 2004, 27:348-64.

15. Clayton D, Chapman J, Cooper J: Use of unphased multilocus genotype data in indirect association studies. Genet Epidemiol 2004, 27:415-28.

16. Dupont WD, Plummer WD Jr: Power and sample size calculations for studies involving linear regression. Control Clin Trials 1998, 19:589-601.

17. Antoniou AC, Easton DF: Polygenic inheritance of breast cancer: Implications for design of association studies. Genet Epidemiol 2003, 25:190-202.

18. Houlston RS, Peto J: The future of association studies of common cancers. Hum Genet 2003, 112:434-435.

19. Pastinen $\mathrm{T}$, Hudson TJ: Cis-acting regulatory variation in the human genome. Science 2004, 306:647-650.

20. Loktionov A: Common gene polymorphisms, cancer progression and prognosis. Cancer Lett 2004, 208:1-33. 